\title{
Effects of in vitro endochondral priming and pre-vascularisation of human MSC cellular aggregates in vivo
}

\author{
Fiona E. Freeman', Ashley B. Allen², Hazel Y. Stevens³, Robert E. Guldberg ${ }^{3}$ and Laoise M. McNamara**
}

\begin{abstract}
Introduction: During endochondral ossification, both the production of a cartilage template and the subsequent vascularisation of that template are essential precursors to bone tissue formation. Recent studies have found the application of both chondrogenic and vascular priming of mesenchymal stem cells (MSCs) enhanced the mineralisation potential of MSCs in vitro whilst also allowing for immature vessel formation. However, the in vivo viability, vascularisation and mineralisation potential of MSC aggregates that have been pre-conditioned in vitro by a combination of chondrogenic and vascular priming, has yet to be established. In this study, we test the hypothesis that a tissue regeneration approach that incorporates both chondrogenic priming of MSCs, to first form a cartilage template, and subsequent pre-vascularisation of the cartilage constructs, by co-culture with human umbilical vein endothelial cells (HUVECs) in vitro, will improve vessel infiltration and thus mineral formation once implanted in vivo.
\end{abstract}

Methods: Human MSCs were chondrogenically primed for 21 days, after which they were co-cultured with MSCs and HUVECs and cultured in endothelial growth medium for another 21 days. These aggregates were then implanted subcutaneously in nude rats for 4 weeks. We used a combination of bioluminescent imaging, microcomputed tomography, histology (Masson's trichrome and Alizarin Red) and immunohistochemistry (CD31, CD146, and a-smooth actin) to assess the vascularisation and mineralisation potential of these MSC aggregates in vivo.

Results: Pre-vascularised cartilaginous aggregates were found to have mature endogenous vessels (indicated by a-smooth muscle actin walls and erythrocytes) after 4 weeks subcutaneous implantation, and also viable human MSCs (detected by bioluminescent imaging) 21 days after subcutaneous implantation. In contrast, aggregates that were not pre-vascularised had no vessels within the aggregate interior and human MSCs did not remain viable beyond 14 days. Interestingly, the pre-vascularised cartilaginous aggregates were also the only group to have mineralised nodules within the cellular aggregates, whereas mineralisation occurred in the alginate surrounding the aggregates for all other groups.

Conclusions: Taken together these results indicate that a combined chondrogenic priming and pre-vascularisation approach for in vitro culture of MSC aggregates shows enhanced vessel formation and increased mineralisation within the cellular aggregate when implanted subcutaneously in vivo.

Keywords: Tissue engineering, Endochondral ossification, Endothelial cells, Mesenchymal cells, Vasculogenesis, Osteogenesis, Cell viability

\footnotetext{
* Correspondence: laoise.mcnamara@nuigalway.ie

${ }^{1}$ Centre for Biomechanics Research (BMEC), Biomedical Engineering, College

of Engineering and Informatics, National University of Ireland Galway,

Galway, Ireland

Full list of author information is available at the end of the article
}

\section{Biomed Central}

(C) 2015 Freeman et al. Open Access This article is distributed under the terms of the Creative Commons Attribution 4.0 International License (http://creativecommons.org/licenses/by/4.0/), which permits unrestricted use, distribution, and reproduction in any medium, provided you give appropriate credit to the original author(s) and the source, provide a link to the Creative Commons license, and indicate if changes were made. The Creative Commons Public Domain Dedication waiver (http://creativecommons.org/publicdomain/zero/1.0/) applies to the data made available in this article, unless otherwise stated. 


\section{Introduction}

Tissue engineering and regenerative medicine have significant potential to treat bone pathologies by exploiting the capacity for bone progenitors to grow and produce tissue constituents under specific biochemical and physical conditions [1-19]. However, the regenerated bone tissue produced through such approaches is limited, due to the degradation occurring in the centre of the constructs and loss of cell viability due to hypoxia occurring within the constructs, which arise from lack of vascularisation $[13,20-26]$ and a lack of mechanical integrity of the regenerated tissue. As a result such strategies are not yet widely used for clinical treatment of large bone defects.

Endochondral ossification is the process by which all long bones are formed during early fetal development. It relies on the production of a cartilage template, which is followed by vessel invasion. This occurs once the cartilage template has formed; endothelial cells invade through the cartilage canals already present in the developing bone tissue [27-30], and this process typically occurs between 14 and 18 days of embryogenesis [30,31]. Both cartilage template formation and vascularisation must occur before bone tissue can be formed. Recent findings have suggested that mimicking the cartilage template formation phase of the endochondral ossification process, by chondrogenically priming mesenchymal stem cells (MSCs), may be an effective approach to overcome issues such as poor oxygen and nutrient supply in bone tissue-engineered constructs $[26,32-34]$ as chondrocytes are physiologically functional even at reduced oxygen tension [35]. However, even with chondrogenic priming, construct degradation and an uneven distribution of bone mineral have been reported throughout the construct after implantation $[25,26,33]$. In a recent study we found that chondrogenic priming of BALBc mice MSCs and human MSCs in vitro for specific durations (14 and 21 days) can influence their mineralisation capacity and produce a construct that is mineralised throughout the core to a greater degree than culturing the cells in osteogenic growth factors alone [34]. In vivo studies demonstrated that chondrogenically primed constructs seeded with embryonic stem cells [36], chick embryonic stem cells [37] and human MSCs [25, 26, 33, 38] subsequently mineralised and in some cases formed bone marrow cavities $[37,38]$ following subcutaneous implantation in rodent animal models. Chondrogenically primed rat MSCs cultured on a PLGA scaffold were found to have increased bone healing in both a 5-mm and 15-mm rat femur defect [39]. Similar rapid healing was also reported when chondrogenically primed human MSC cellular aggregates were implanted in a 6-mm rat femur defect [40].

Without a suitable vascular supply, cells within tissue engineered constructs lack the necessary requirements to regenerate bone tissue and readily perish when implanted in vivo [41, 42]. In vitro co-culture studies have investigated whether pre-vascularising three-dimensional tissue-engineered constructs, such as trabecular bone [43], polycaprolactone (PCL) [44], poly(LLA-co-DXO) [45], collagen glycosaminoglycan (GAG) [46, 47], and hydroxyapatite [48] scaffolds in vitro, through the coculture of MSCs and human umbilical vein endothelial cells (HUVECs), would allow faster host integration post-implantation [43-48]. It has been shown that prevascular networks can be formed in a subcutaneous animal model in vivo when human MSCs [43, 45, 46, 48] are first co-cultured with HUVECs in vitro. Moreover, in vitro co-culture studies of HUVECs and MSCs have detected an upregulation of the early osteogenic growth factor alkaline phosphatase (ALP) in both two- and threedimensional culture [49-53].

While current bone regeneration strategies have sought to incorporate either the production of the cartilage template or the vascularisation of the construct, no strategy has sought to incorporate both events simultaneously, even though both are crucial precursors for bone formation during endochondral ossification in vivo. In a recent in vitro study, we found that chondrogenic priming (for 21 days) together with co-culture of human MSCs and HUVECs significantly increased the osteogenic potential of the culture compared to chondrogenic priming alone [54]. This study also reported that both MSCs and HUVECs must be added to the formed cartilage template for the formation of rudimentary vessels to occur in vitro. We found that the application of both chondrogenic and vascular priming of MSCs enhanced the mineralisation potential of MSCs in vitro whilst also allowing for immature vessel formation. However, the in vivo viability, vascularisation and mineralisation potential of MSC aggregates that have been pre-conditioned in vitro by a combination of chondrogenic and vascular priming has yet to be established.

In this study, we test the hypothesis that a tissue regeneration approach that incorporates both chondrogenic priming of MSC aggregates, to first form a cartilage template, and subsequent pre-vascularisation of the cartilage constructs, through the co-culture of HUVECs in vitro, will improve cell survival, vessel infiltration and thus mineral formation once implanted in vivo. The specific objectives of this study are to assess these outcome measures within a subcutaneous implantation nude rat model.

\section{Methods}

\section{Cell culture}

Human donor MSCs

Bone marrow-derived human MSCs harvested from two male donors, 20-25 years old, with established multi- 
potency, were commercially available and purchased from the Texas A\&M University Health Science Centre (Temple, TX, USA). As the human MSCs were bought from Texas A\&M University Health Science Centre, all ethical approval was conducted by them. The human MSCs were expanded in minimum essential medium alpha ( $\alpha$ MEM; Invitrogen, Carlsbad, CA, USA) containing $16.7 \%$ fetal bovine serum (FBS; Atlanta Biologicals, Lawrenceville, GA, USA) and 100 units/mL penicillin/ $100 \mu \mathrm{g} / \mathrm{mL}$ streptomycin/2 mM L-glutamine (PSL; Invitrogen) at $37{ }^{\circ} \mathrm{C}$ and $5 \% \mathrm{CO}_{2}$. For all cell culture performed in this study, cell culture medium was changed twice weekly unless stated otherwise. At passage 2, cells from each donor were detached using $0.25 \%$ trypsinethylenediaminetetraacetic acid (EDTA; Invitrogen) and combined 1:1 to produce a pooled human MSC population. MSCs were further cultured to passage 3-4.

\section{Cell labelling}

Human MSCs were co-transduced using lentiviral vector containing green fluorescent protein (GFP) and firefly luciferase (Luc) downstream of the ubiquitin promoter as previously described [55-57]. Briefly, human MSCs were suspended in polybrene and a viral vector at a multiplicity of infection (MOI) of 20 and incubated in flasks at a density of 10,000 cells $/ \mathrm{cm}^{2}$ overnight (Sigma, St. Louis, MO, USA). Medium was changed daily for 3 days, after which the labelling efficiency of GFP/Luc was determined using fluorescent microscopy. GFP/Luc-labelled human MSCs were replated at a seeding density of $500 \mathrm{cells} / \mathrm{cm}^{2}$ and were further cultured to passage 3-4. These GFP/Luc-labelled human MSCs were only used in the constructs tested for bioluminescent imaging (BLI).

\section{HUVEC culture}

HUVECs were commercially available and purchased from Lonza (Maryland, USA) and cultured in Clonetics endothelial growth medium (EGM) SingleQuotes (Lonza). As the HUVECs were purchased from Lonza, all necessary ethical approval was conducted by them. Media was replaced every 3 days and, upon reaching 80-90\% confluency, cells were passaged using $0.25 \%$ trypsin-EDTA (Invitrogen). HUVECs were further cultured to passage 3.

\section{Aggregate formation}

Once the human MSCs (labelled and unlabelled) reached a confluency of $\sim 80 \%$ the cells were trypsinised, counted, and centrifuged at $650 \mathrm{~g}$ at a temperature of $22{ }^{\circ} \mathrm{C}$ for $5 \mathrm{~min}$. The cells were then resuspended in expansion media at a density of $0.25 \times 10^{6}$ cells $/ \mathrm{mL}$. This cell suspension was divided into $1.5 \mathrm{~mL}$ tubes so that there were 250,000 cells in each tube, and these were then centrifuged for 5 mins (Eppendorf Centrifuge
5430R; Vashaw Scientific, Norcross, GA, USA) at $400 \mathrm{~g}$ to create cell aggregates. The media was removed from the tube carefully, so as to avoid the newly formed aggregate, and $0.5 \mathrm{~mL}$ of chondrogenic media was added. Chondrogenic medium consisted of a chemically defined medium, which contained high-glucose Dulbecco's modified Eagle's medium (DMEM) GlutaMAXTM (Invitrogen), $10 \mathrm{ng} / \mathrm{mL}$ transforming growth factor (TGF)- $\beta 3$ (Invitrogen), $50 \mu \mathrm{g} / \mathrm{mL}$ ascorbic acid (Sigma Aldrich), $4.7 \mu \mathrm{g} / \mathrm{mL}$ linoleic acid-oleic acid (Sigma Aldrich), $100 \mathrm{nM}$ dexamethasone (Sigma Aldrich) and $1 \times$ insulin-transferrin-selenium (ITS; Invitrogen). For all experiments aggregate cultures were fed twice per week by performing a $50 \%$ medium exchange. During each feed the aggregates were agitated, so as to prevent them from adhering to the micro-tube. This was achieved through aspirating the media beneath the aggregate with a micro-pipette.

After 21 days, the aggregates were separated into three different experimental conditions: 1) CP21 HUVECs (aggregates were chondrogenically primed for a period of 21 days and then cultured in EGM media for a further 21 days; hereafter known as the Cartilage Template group); 2) CP21 + HUVECs (aggregates were chondrogenically primed for 21 days after which 250,000 suspended HUVECs in EGM were added to the cellular aggregate and cultured in EGM for further 21 days; hereafter known as the Co-Culture Cartilage Template group); and 3) CP21+HUVECs:MSCs (aggregates were chondrogenically primed for 21 days after which 250,000 suspended HUVECs and MSCs at a ratio of 1:1 (125,000:125,000 cells) in EGM were added and further cultured in EGM for 21 days; hereafter known as the Pre-vascularised Cartilage Template group); see Fig. 1.

For the co-culture groups, confluent layers of HUVECs/MSCs were trypsinised and counted. Cells were suspended depending on experimental conditions so that there were $0.5 \times 10^{6}$ cells $/ \mathrm{mL}$. In the case of the CP21 + HUVECs:MSCs, the ratio of cells was 1:1 HUVECs:MSCs. Both the HUVECs and the MSCs added were at passage 3 , which was the same passage of the MSCs used to form the original cellular aggregate. The cells were suspended in EGM media containing osteogenic growth factors and $20 \%$ methocel, from a stock solution that was generated by dissolving $6 \mathrm{~g}$ carboxymethylcellulose (Sigma Aldrich) in $500 \mathrm{~mL}$ DMEM as previously described [58]. The addition of the methocel to the media increases the viscosity of the media and promotes the attachment of the cells to the already formed aggregate. After $24 \mathrm{~h}$ the medium that contained methocel was removed and was replaced with EGM media alone and this EGM media alone was used for the further 20 days of culture. 
A

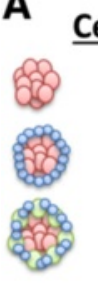

Cellular Groups

Chondrogenic Priming -HUVECs (Cartilage Template)

Chondrogenic Priming + HUVECs (Co-culture Cartilage Template) Chondrogenic Priming + HUVECs:MSCs

(Pre-vascularised Cartilage Template)
Hydrogel Methodology

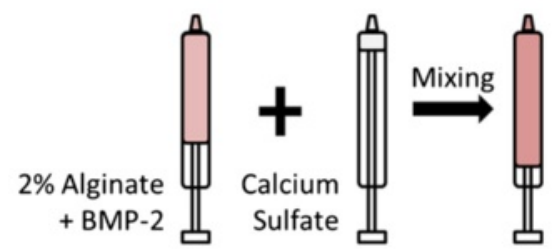

\section{B}

\section{Experimental Setup}
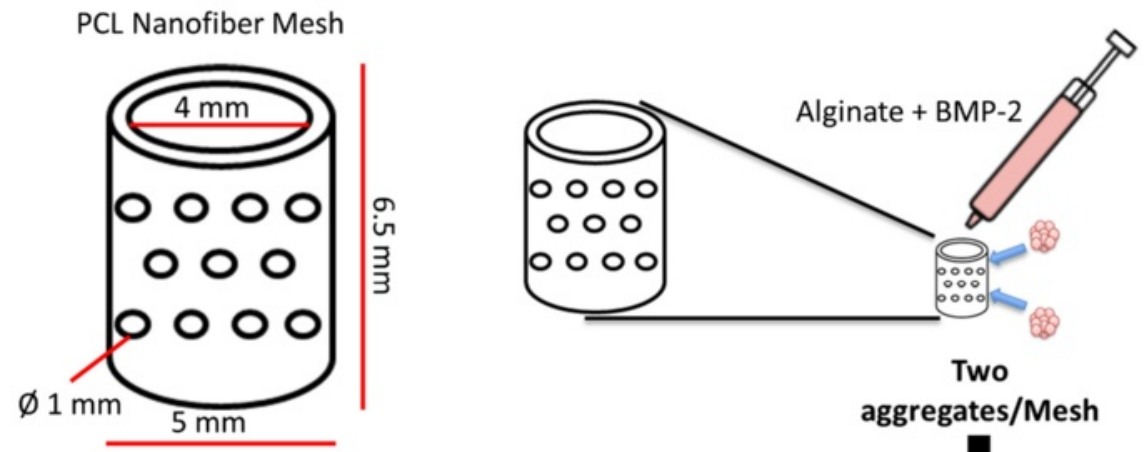

aggregates/Mesh

C

$\underline{\text { Timeline }}$

Subcutaneous Implantation

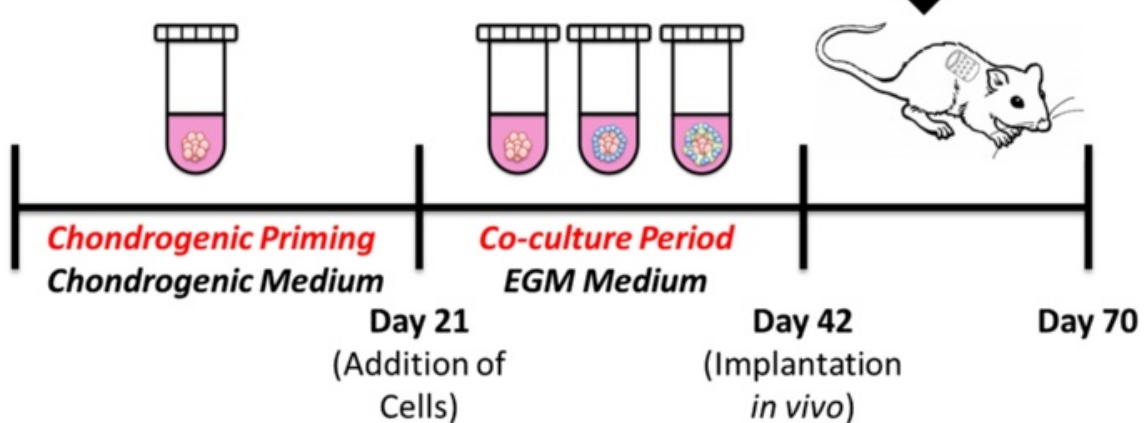

Fig. 1 Schematic of the $\mathbf{a}$ cellular groups and hydrogel methodology, $\mathbf{b}$ experimental setup and $\mathbf{c}$ timeline of the experiment. BMP Bone morphogenetic protein, EGM Endothelial growth medium, HUVEC Human umbilical vein endothelial cell, MSC Mesenchymal stem cell, PCL Polycaprolactone

\section{Construct preparation}

After 42 days of in vitro culture, the primed aggregates were prepared for implantation. A dual syringe approach, previously described by Kolambkar et al. [59], was adapted to imbed the cellular aggregates within hydrogels. Briefly, functionalised alginate (FMC Biopolymer; Sandvik, Norway) containing bone morphogenetic protein (BMP)-2 (Pfizer, MA, USA) at a concentration of $1.6 \mu \mathrm{g} / 100 \mu \mathrm{L}$ was cross-linked by adding calcium sulphate (Sigma) to a final concentration of $8.4 \mathrm{mg} / \mathrm{mL}$. Constructs were prepared by injecting $100 \mu \mathrm{L}$ of crosslinked alginate into an electrospun, PCL nanofibre mesh tube [59], and two cellular aggregates from each group were placed within each alginate/mesh construct (Fig. 1). One group, which contained no aggregates within the mesh, was used as an acellular group (known as the Alginate group). These constructs were then incubated in culture medium within a 24-well ultralow-attachment plate (Corning, Lowell, MA, USA) for $2-6 \mathrm{~h}$ prior to implantation.

\section{Surgical procedures}

All animal procedures were ethically approved and conducted in accordance with the Georgia Institute of 
Technology Institutional Animal Care and Use Committee protocol (\#A13023). Ten 11-week-old female, athymic nude rats (Charles River Labs, Wilmington, MA, USA) were anaesthetised using isoflurane. Two incisions were made in the skin slightly lateral to the spine of each animal and a custom made tunnelling device was used to create four subcutaneous pockets. One construct (from each of the four groups) was placed in each pocket. Constructs were implanted in a balanced manner, such that each group contained an implant placed at each of the subcutaneous locations and samples were randomly distributed across the operated animals. Once the four constructs were implanted, incisions were closed using suture and wound clips.

\section{Bioluminescent imaging}

Two rats received constructs with aggregates formed from GFP/Luc-labelled human MSCs (as discussed above) and were maintained under anaesthesia to perform day 0 BLI.

BLI was performed on the animals on days $0,7,14$, and 21 , following a previously developed approach [57]. Briefly rats were anaesthetised using isoflurane and $300 \mu \mathrm{L}$ luciferin was injected subcutaneously in close proximity to the construct site. After $30 \mathrm{~min}$, animals were positioned with their lateral side facing up and scanned using an IVIS Lumina machine (Caliper Life Sciences, Hopkinton, MA, USA). The animals were then repositioned so that their other side could be scanned. BLI images were evaluated by demarcation of a $4 \mathrm{~cm}^{2}$ elliptical region of interest (ROI) centred on each construct using Living Image software version 3.2 (Caliper Life Sciences). BLI counts were normalised by exposure time and ROI for each sample.

\section{Micro-computed tomography imaging}

At 4 weeks post-surgery, eight rats (each rat contained the four groups) underwent a vascular perfusion protocol modified from that developed by Duvall et al. [60] and Allen et al. [57]. Briefly, the rats were put under anaesthesia and maintained at $4 \%$ isoflurane. Once anaesthetised, the thoracic cavity was opened to insert an 18 gauge catheter (SURFLO Teflon IV catheter; Terumuo Medical, Somerset, NJ, USA) through the left ventricle of the heart into the ascending aorta. The inferior cava was cut and $0.9 \%$ saline was perfused through the vasculature using a peristaltic pump (Masterflex, Cole Parmer, Vernon Hills, IL, USA) until the vasculature system was completely flushed clear. A solution of $0.9 \%$ saline containing $0.4 \%$ $(\mathrm{w} / \mathrm{v})$ papaverin hydrochloride was then perfused followed by $10 \%$ neutral buffered formalin (NBF) for $5 \mathrm{~min}$. Animals received a final perfusion of 20-25 mL radiopaque contrast agent Microfil (Flow Tech, Carver, MA, USA) and were left at $4{ }^{\circ} \mathrm{C}$ overnight. In this way, animals were euthanised by the combined effects of isoflurane overdose and exsanguination. Explants were extracted and incubated in NBF for $24 \mathrm{~h}$ before being imaged via microcomputed tomography $(\mu \mathrm{CT})$ scans on a MicroCT42 (Scanco Medical, Brüttisellen, Switzerland) at $55 \mathrm{kVp}$, $145 \mu \mathrm{A}$, and a $12 \mu \mathrm{m}$ voxel size. The volume of interest was defined as the construct and the minimal tissue surrounding the construct. Microfil has the same threshold as bone mineral and therefore to segment perfused vasculature from mineralised tissue within each construct two scans were analysed: calcified construct versus decalcified construct. The calcified constructs were scanned and post-processed using a threshold value that accurately depicted both the mineral content and the vessel volume by visual inspection of the two-dimensional greyscale tomograms (Scanco Medical MicroCT42). Noise was removed using a low-pass Gaussian filter (sigma $=1.2$, support $=2$ ). Next samples were decalcified in Immunocal (Formic acid bone Decalcifier, Decal Chemical Corporation) for 1 week with the decalcification solution replaced every day (decalcified constructs). After 1 week these decalcified constructs were scanned using the same settings, and post-processed at the same threshold as the calcified constructs to determine mineral content. Mineralised tissue content was determined by subtracting the bone volume of the decalcified scans from the calcified scans. Next the decalcified scans were post-processed at a threshold value that accurately depicted just the vessel volume upon visual inspection of the two-dimensional greyscale tomograms.

\section{Histochemical analysis}

Following $\mu \mathrm{CT}$ scanning the samples were dehydrated and embedded in paraffin using an automatic tissue processor (Excelsior ES tissue processor, Thermo Scientific, Austin, TX, USA). All samples were sectioned with a thickness of $8 \mu \mathrm{m}$ using a rotary microtome (Leica Microtome RM2235, Leica). Sections were stained with Masson's Trichrome and Alizarin Red (all Sigma Aldrich).

\section{Immunohistochemical analysis}

Immunohistochemical analysis was used to detect CD31, CD146 and $\alpha$-smooth muscle actin. Sections were deparaffinised overnight before a series of rehydration steps through varying ethanol grades (100-50 \%). The samples were then treated with $40 \mu \mathrm{g} / \mathrm{mL}$ proteinase $\mathrm{K}$ for $20 \mathrm{~min}$ at $37^{\circ} \mathrm{C}$ (Sigma Aldrich), rinsed with phosphatebuffered saline (PBS)-Tween and blocked with PBS with $1 \% \mathrm{w} / \mathrm{v}$ bovine serum albumin (BSA) and $3 \% \mathrm{w} / \mathrm{v}$ normal goat serum (NGS; Sigma Aldrich) for $60 \mathrm{~min}$. Sections were then incubated overnight at $4{ }^{\circ} \mathrm{C}$ with either rabbit polyclonal anti-CD31 (ab28364 Abcam, 1:50) or rabbit monoclonal anti-CD146 (ab75769 Abcam, 1:250). 
After three washing steps with PBS containing $1 \% \mathrm{w} / \mathrm{v}$ BSA the sections were incubated with Dylight 488 goat anti-rabbit secondary antibody (Jackson Immunoresearch, 115-485-209, 1/200), for 1 hour at room temperature in the dark. The samples were washed three times in PBS with $1 \% \mathrm{w} / \mathrm{v}$ BSA, and the slides were then incubated overnight at $4{ }^{\circ} \mathrm{C}$ with mouse monoclonal anti- $\alpha$-smooth muscle actin antibody (ab7817 Abcam, 1:50). After three washing steps with PBS with $1 \% \mathrm{w} / \mathrm{v}$ BSA the sections were incubated with Dylight549 goat anti-mouse secondary antibody (Jackson Immunoresearch, 115-505-062, 1/200), for 1 hour at room temperature in the dark. Finally samples were washed three times with PBS with $1 \% \mathrm{w} / \mathrm{v}$ BSA and the sections were mounted using 4',6-diamidino-2-phenylindole (DAPI) mounting media (Sigma Aldrich).

\section{Statistical analysis}

Results are expressed as mean \pm standard error. All $\mu \mathrm{CT}$ quantitative analyses were examined using one-way analyses of variance (ANOVA) with the addition of Tukey's correction for multiple comparisons testing. BLI quantitative analysis was examined using two-way ANOVA with the addition of Tukey's correction for multiple comparisons testing. All analyses were performed using GraphPad (GraphPad Software, La Jolla California USA, www.graphpad.com). For all comparisons, the level of significance was $p \leq 0.05$.

\section{Results}

\section{Construct morphology}

\section{Prior to implantation}

All three experimental groups stained positive blue for sGAG and Alizarin Red prior to implantation after 42 days of culture (Fig. 2a,b). There was no significant difference in sGAG or calcium production after the 6 weeks of culture.

There was no positive (green) staining for CD31+ in the CP21 - HUVECs group cultured as there were no endothelial cells present (Fig. 2c). However, for both the CP21 + HUVECs and the CP21 + HUVECs:MSCs groups there was positive (green) staining seen around the periphery (indicated by arrows in Fig. 2c) and, after 3 weeks of co-culture, both groups had positive green staining present within the centre of the aggregates. However, the CP21 + HUVECs:MSCs group was the only group to have structures characterised by a circular CD31+ positive wall with irregularly shaped nuclei present within the lumen (indicated by arrows in Fig. 2c).

\section{Post implantation}

All aggregates were identifiable as a clear circular bundle of cells present within the nanofibre mesh (as indicated by the letter $\mathrm{A}$ in Fig. 3) after 4 weeks in vivo. The aggregates are predominately surrounded by alginate and host cells (Fig. 3). As expected there was evidence of degradation in the Cartilage Template and the Coculture Cartilage Template groups, as indicated by the channels present within the centre of the aggregates (indicated by the letter D in Fig. 3), along with the buildup of fibrous collagen tissue surrounding the aggregate (indicated by the letter $\mathrm{C}$ in Fig. 3). However, in the Prevascularised Cartilage Template group the degradation was minimal (Fig. 3). There was also positive collagen staining present in all of the aggregates.

\section{Mineral formation}

Quantitative mineralisation of the constructs and the surrounding tissue in the hydrogel was analysed from the reconstructed $\mu \mathrm{CT}$ data to determine mineral volume. All groups produced mineral volume between 0.5 and $0.8 \mathrm{~mm}^{3}$; however, there was no significant difference between any of the groups after 4 weeks of implantation (Fig. 4).

Positive Alizarin Red staining was present in all of the groups; however, the location of the mineral differed by group. The only group to have mineralisation nodules present within the aggregate itself was the Prevascularised Cartilage Template group. All of the other groups only had mineralisation nodules present in the surrounding alginate, as seen in Fig. 5. Some of these mineralisation nodules were present in close proximity to mature blood vessels, as indicated in Fig. 5 by the arrows.

\section{Cell viability}

BLI data obtained over the course of the study showed that the live cell number from the original cellular aggregate decreased in all groups from the day of surgery to 2 weeks after implantation (see Fig. 6a,b). However, there was a significantly higher BLI signal in the Prevascularised Cartilage Template group and Co-culture Cartilage Template group $(p<0.05)$ compared to the Alginate group at both day 0 and day 7 . The Prevascularised Cartilage Template group also retained more cells compared to the other groups at day 7 (88\% vs. $82-20.5 \%)$ and day 14 (27.4 \% vs. $18.3-1.7 \%)$ and by day 21 there was more viable human MSCs present in the Pre-vascularised Cartilage Template group compared to both the Alginate $(p=0.1)$ and Co-culture Cartilage Template groups $(p=0.13)$ (Fig. 6b). BLI imaging was performed on day 28 ; however, no detectable signal was found.

\section{Vessel infiltration}

$\mu \mathrm{CT}$ reconstruction of the explant vasculature illustrated the presence of host blood vessels surrounding the construct and infiltrating the construct through the holes 

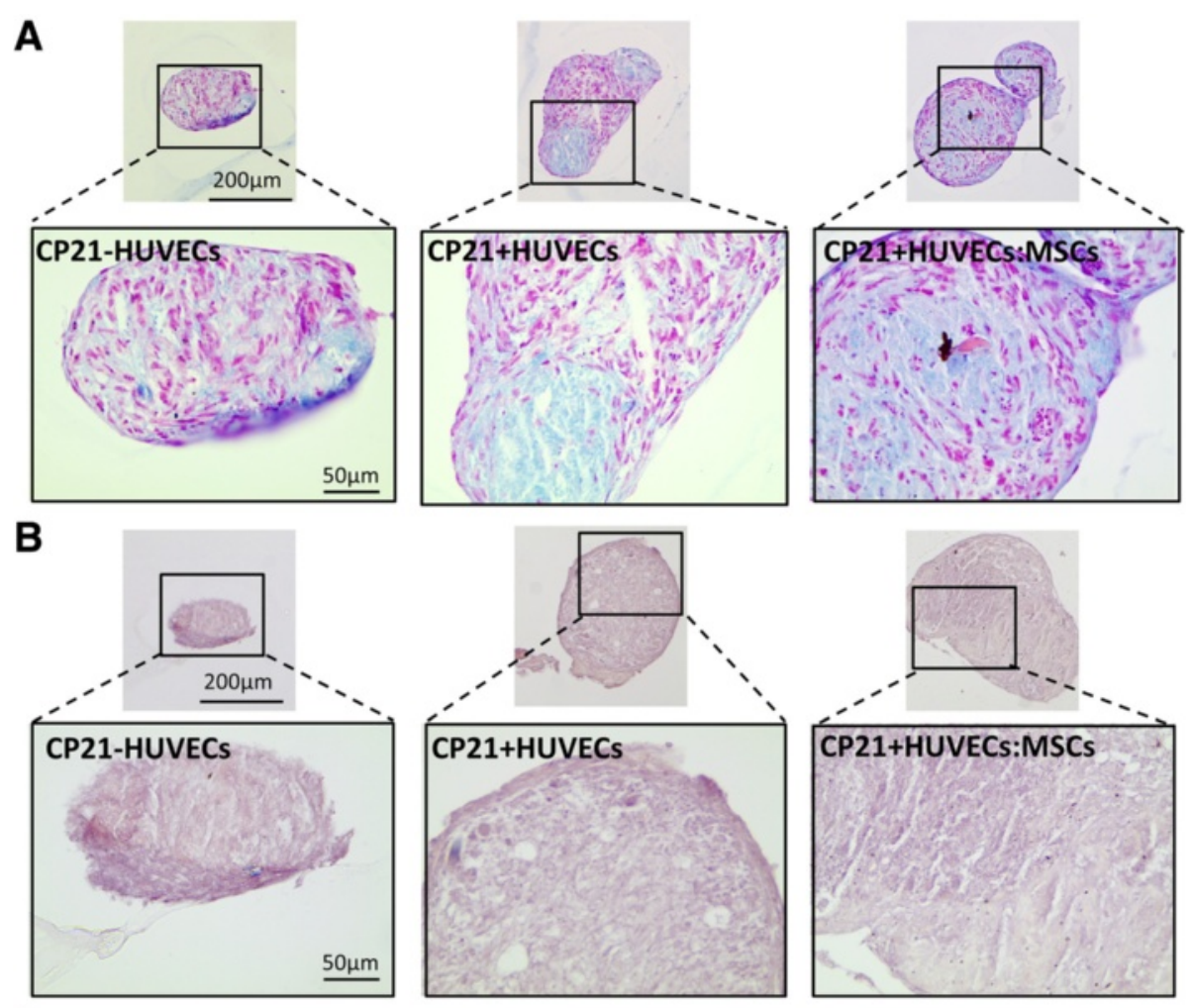

C
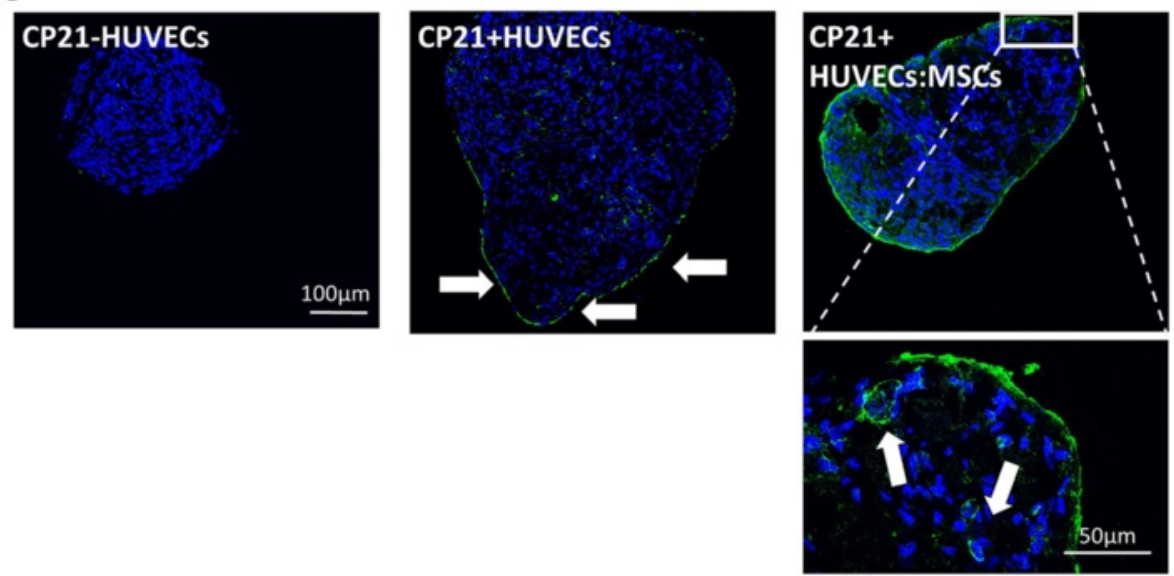

Fig. 2 a Alcian Blue and $\mathbf{b}$ Alizarin Red staining of all three groups on the day of implantation (following 3 weeks of in vitro priming). Images were taken at a magnification of 10X and 40X. c Representative images of CD31+ (green) stained sections in the CP21 + HUVECs:MSCs group prior to implantation. Arrows denote the presence of positive CD31+ staining. Each section is $8 \mu \mathrm{m}$ thick and each of the images was taken at a magnification of 20x and 60x. Nuclear counterstain: DAPI (blue). CP21 Chondrogenically primedat day 21, HUVEC Human umbilical vein endothelial cell, MSC Mesenchymal stem cell

present within the nanofibre mesh (Fig. 7a). Vessel volume was quantified in two ways: 1) total vessel volume; and 2) average vessel diameter. After 4 weeks in vivo there was no significant difference in total vessel volume or average vessel diameter between any of the groups (Fig. 8a,b). To further analyse the data a vessel diameter of $0.15 \mathrm{~mm}(150 \mu \mathrm{m})$ was chosen as a threshold to distinguish between thick and thin vessels and preclude smaller structures (that were unlikely to be mature vessels) from obscuring the results of the analysis. The threshold was chosen on the basis of our immunostaining (described in detail below), which revealed that positively stained $\alpha$-smooth actin and CD31 and structures with a visible lumen had diameters in the range of $150 \mu \mathrm{m}$ (see Figs. 9 and 10, described in detail below). Moreover, the majority of vessels in a Sprague-Dawley 


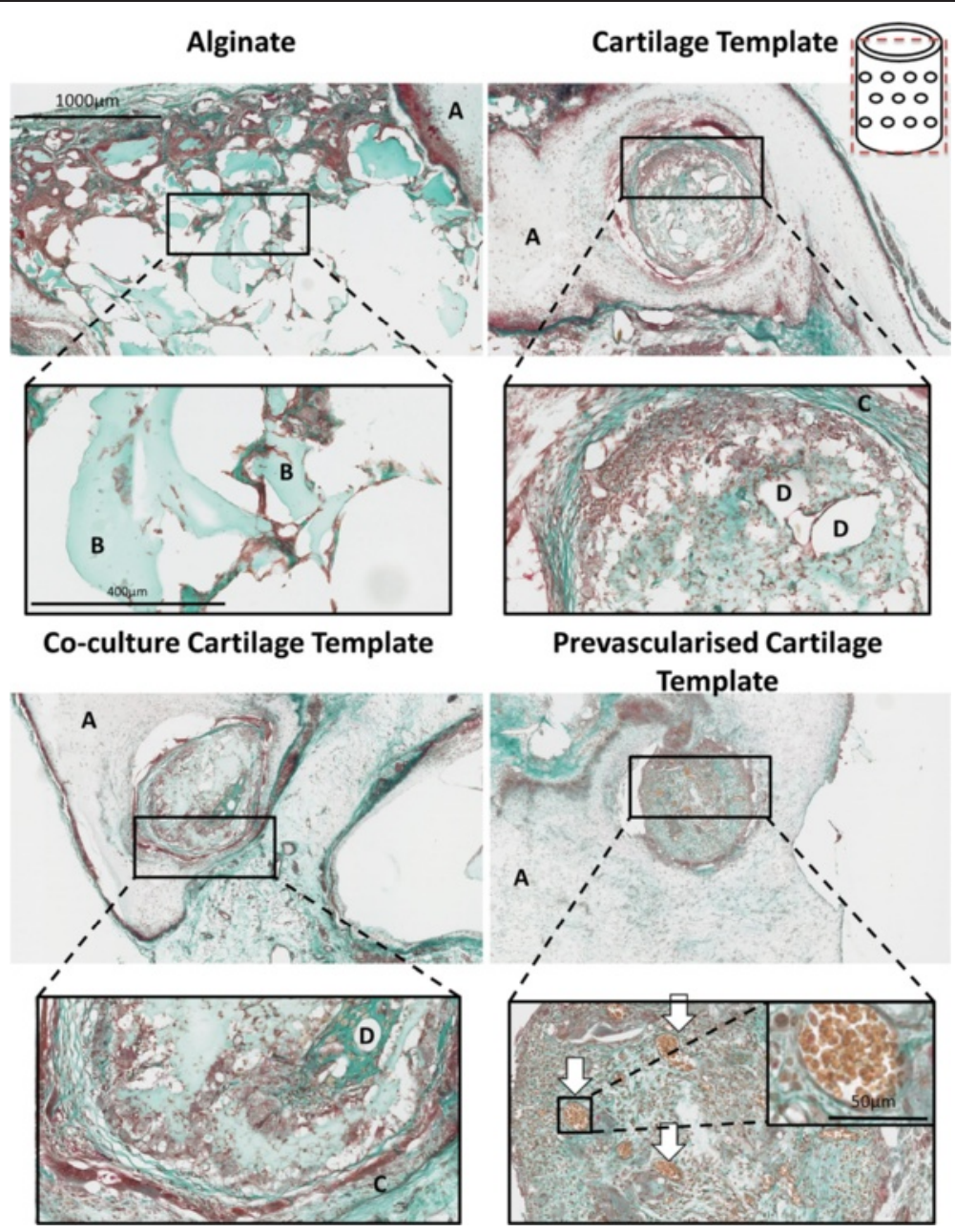

Fig. 3 Masson's Trichrome of the groups after 4 weeks implantation. Images were taken at $5 x, 20 x$ and $40 x$. Schematic of the plane in which the section was taken in in the top right corner. A nanofibre mesh, $B$ islands of alginate, C sGAG rich encapsulation, $D$ area of degradation, arrows vessels complete with red blood cells

rat femora are in the range of $120-150 \mu \mathrm{m}[61]$ and the average vessel diameter achieved within a bone tissueengineering scaffold implanted in a rabbit alveolar bone defect was $152 \mu \mathrm{m}$ by 4 weeks [62]. For both the Cartilage Template and the Pre-vascularised Cartilage template groups a large proportion of the vessels were thicker than $0.15 \mathrm{~mm}$. When only vessels with a diameter greater than $0.15 \mathrm{~mm}$ are considered, in both the alginate and the Coculture Cartilage Template group only three out of eight rats had vessels greater than $0.15 \mathrm{~mm}$. These vessels only accounted for $7 \%$ of the overall vessels within the construct. However, in both the Cartilage Template and Prevascularised Cartilage Template group five out of eight rats had vessels present with a greater diameter than $0.15 \mathrm{~mm}$ and these vessels accounted for up to $14 \%$ of the overall vessels seen within the construct (see Fig. 7b).

Histological staining revealed that there was little vessel formation present within the Cartilage Template and
Co-culture Cartilage Template aggregates, but most of the vessels were found outside the aggregates within the alginate (Fig. 3). However, the Pre-vascularised Cartilage Template group was the only group to contain vessels within the aggregate itself complete with red blood cells (Fig. 3, denoted by the arrows).

Immunohistochemical analysis confirmed that mature vessels were present in the surrounding alginate in all of the groups, as indicated by the $\alpha$-smooth actin staining (Figs. 9 and 10). In contrast the Pre-vascularised Cartilage Template group had mature vessels present within the centre of the aggregates, rather than around the periphery in the surrounding alginate. CD146 and CD31 staining, both endothelial cell markers, revealed that, for both the Co-culture Cartilage Template and the Prevascularised Cartilage Template groups, endothelial cells were involved in the formation of these vessels. Moreover, CD31 positive stained cells were present within the 


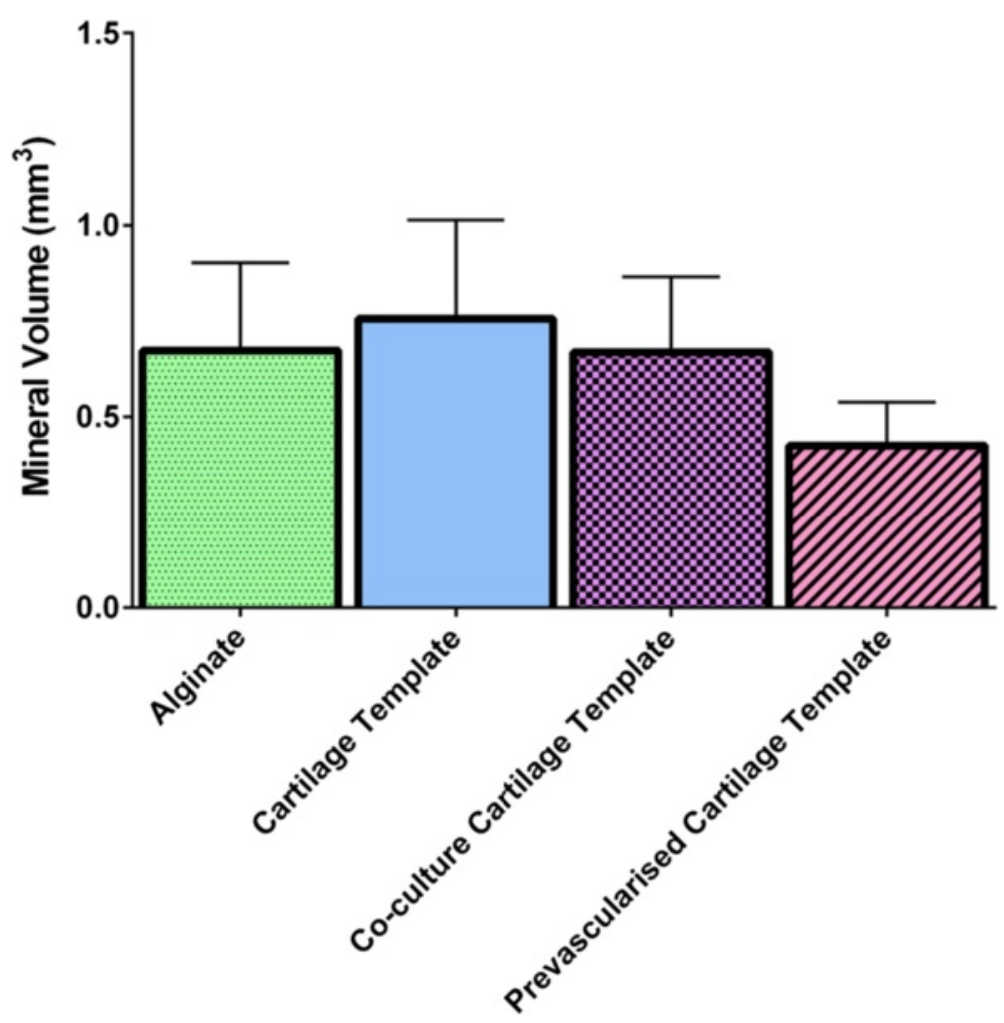

Fig. 4 Total mineral volume. Error bars denote standard error $(n=8)$

structure of some of the vessels (Figs. 9 and 10) indicating that the implanted human endothelial stem cells were involved in the formation of these vessels, as CD31 is only present in human endothelial cells. The staining also showed CD31 positive stained cells were not only present on the periphery of the aggregates but were also present within the surrounding alginate.

\section{Discussion}

This study investigated whether a tissue regeneration approach that incorporates both chondrogenic priming of MSCs to first form a cartilage template, and subsequent pre-vascularisation of the cartilage constructs through the co-culture of HUVECs in vitro, would improve the survival of implanted cells, leading to vessel infiltration and thus mineral formation once implanted subcutaneously in vivo. Our results showed that the prevascularised cartilaginous aggregates successfully developed mature vessels (as indicated by $\alpha$-smooth muscle actin walls and red blood vessels) within the aggregates and retained viable cells from the original aggregate (as indicated by BLI signalling) 21 days after subcutaneous implantation. The pre-vascularised cartilaginous aggregates were also the only aggregates to have mineralisation nodules present within the aggregates. In contrast, chondrogenically primed aggregates, with and without HUVECS, did not have viable cells remaining from the original aggregate after 14 days, had a high vessel volume, but these vessels were not present within the aggregate, and only had mineralisation nodules present in the alginate surrounding the aggregates. Collectively, these results indicate that pre-vascularised cartilaginous aggregates survive for a longer duration following subcutaneous implantation in vivo compared to all other groups, and also that these cellular aggregates contribute to the formation of vessels, with $\alpha$-smooth muscle actin walls and red blood cells, and increased mineralisation deposition within the construct, which was not observed in aggregates that were not subjected to a combination of chondrogenic priming and pre-vascularisation.

A possible limitation of the study is that MSCs from two male donors were pooled and we did not directly explore whether the human MSCs displayed a donordependent response to mineral formation. Previous studies have seen donor variability in the expression of osteogenic growth factors both in vitro [63] and mineral formation in vivo [64]. However, the control groups also contained pooled cells, so the differences observed between the groups cannot be explained by donor variability. A second limitation is that we used MSCs and HUVECs from different donors rather than acquiring both cell types from the same donor. However, it was not feasible to obtain the necessary cell numbers to perform the entire experiment, involving multiple 

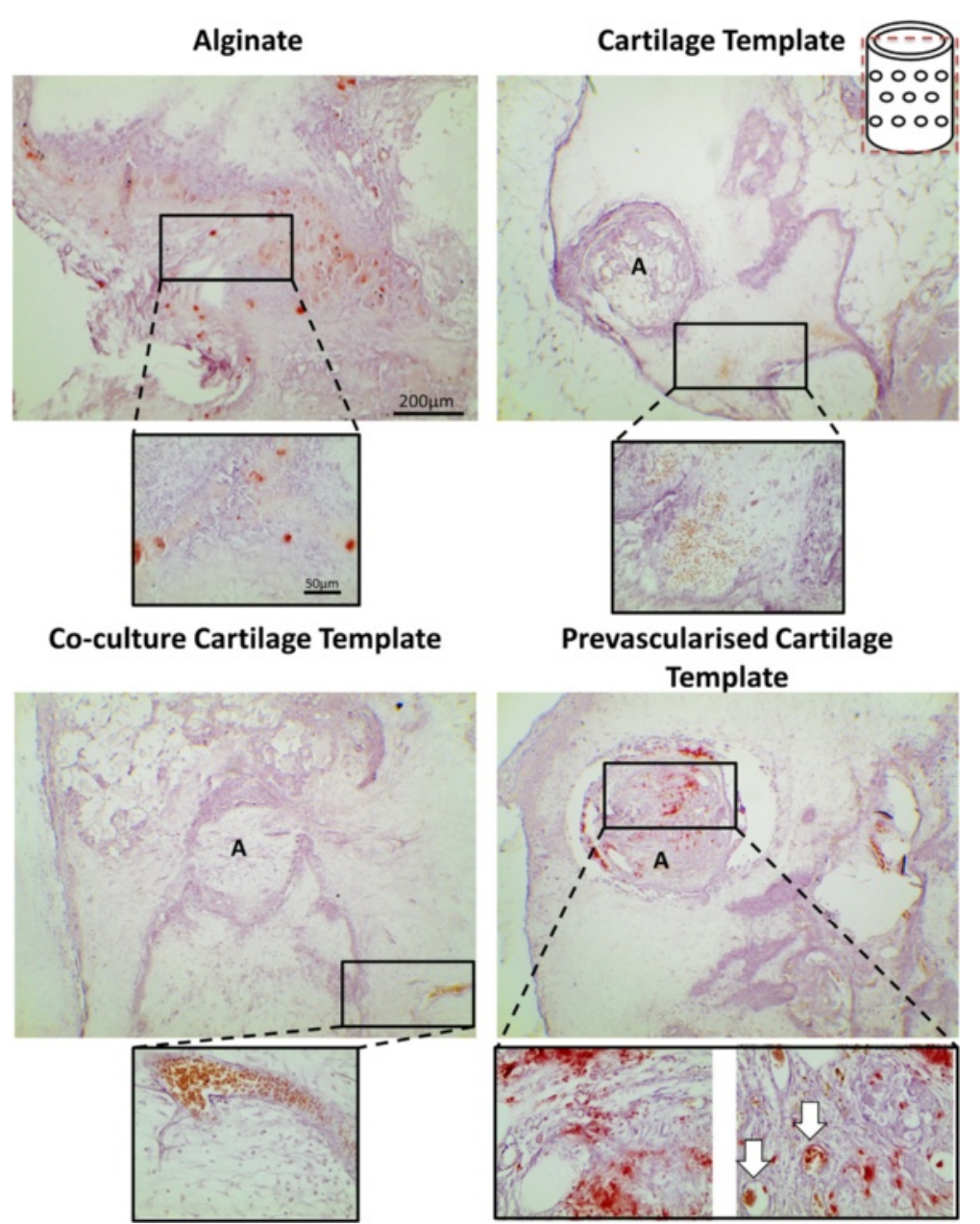

Fig. 5 Alizarin Red staining of the groups after 4 weeks implantation. Images were taken at $4 \times$ and $40 x$. Schematic of the plane in which the section was taken in in the top right corner. Red staining mineralisation nodules present, A aggregates present within the alginate, arrows vessels present.

aggregates and priming groups, using cells sourced from the same donors. Future studies could investigate the in vivo potential of one of these groups (i.e. the Prevascularised Cartilage Template group) using cells from the same donor source to fully understand the clinical relevance of the approach. Another potential limitation was the length of time the samples were examined for mineral formation (4 weeks). Previous ectopic bone formation models indicate that little to no bone formation will occur until approximately 8 weeks [25, 26, 33, 36-38]. The choice of the 4-week time point allowed us to see both early mineral formation and vessel infiltration and was able to distinguish differences at this early time point. Future studies should investigate the long-term effect of subcutaneous implantation of the pre-vascularised cartilaginous aggregates in order to fully understand their mineralisation potential. Finally, the nanofibre mesh/alginate delivery system with osteogenic growth factors (BMP-2) was used to ensure the retrieval of the aggregates after
4 weeks in vivo, which has proved challenging in other subcutaneous implantation studies [25, 26, 33]. However, as we included an acellular control group, we clearly showed that the results obtained could not be explained by the addition of BMP-2 alone, but that the addition of the cells leads to the differences seen between the groups.

Current bone tissue engineering strategies are limited by challenges arising due to lack of nutrient delivery and waste removal arising from the lack of vasculature [13, 20-26]. Our recent in vitro study reported that a combination of chondrogenic priming and co-culture of human MSCs and HUVECs can lead to the formation of rudimentary vessels and significantly increased the in vitro osteogenic potential of MSC aggregates [54]. Other studies have investigated whether pre-vascularising trabecular bone [43], PCL [44], poly(LLA-co-DXO) [45], collagen GAG [46, 47], and hydroxyapatite [48] scaffolds in vitro would allow faster host integration postimplantation and reported that microvascular networks 


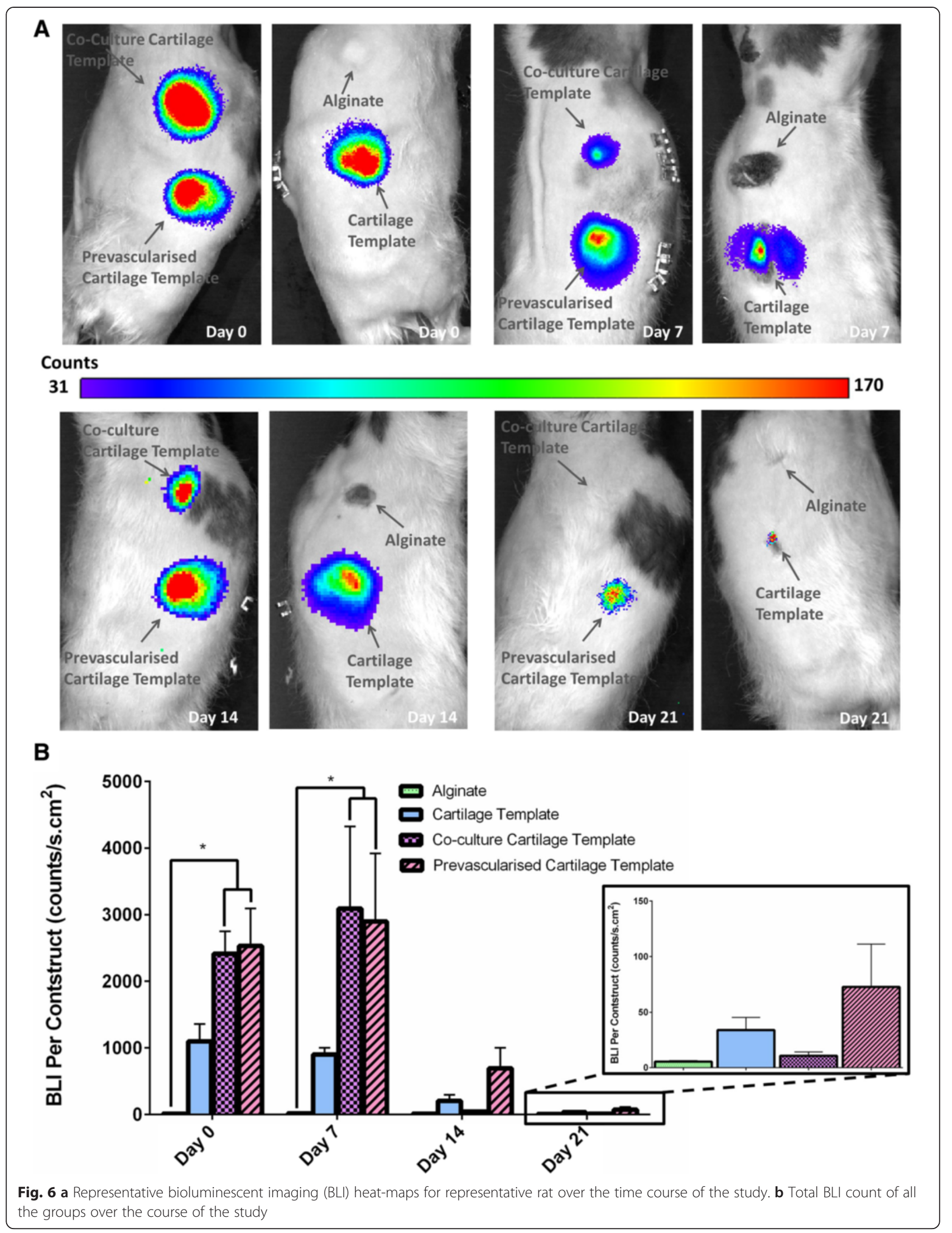



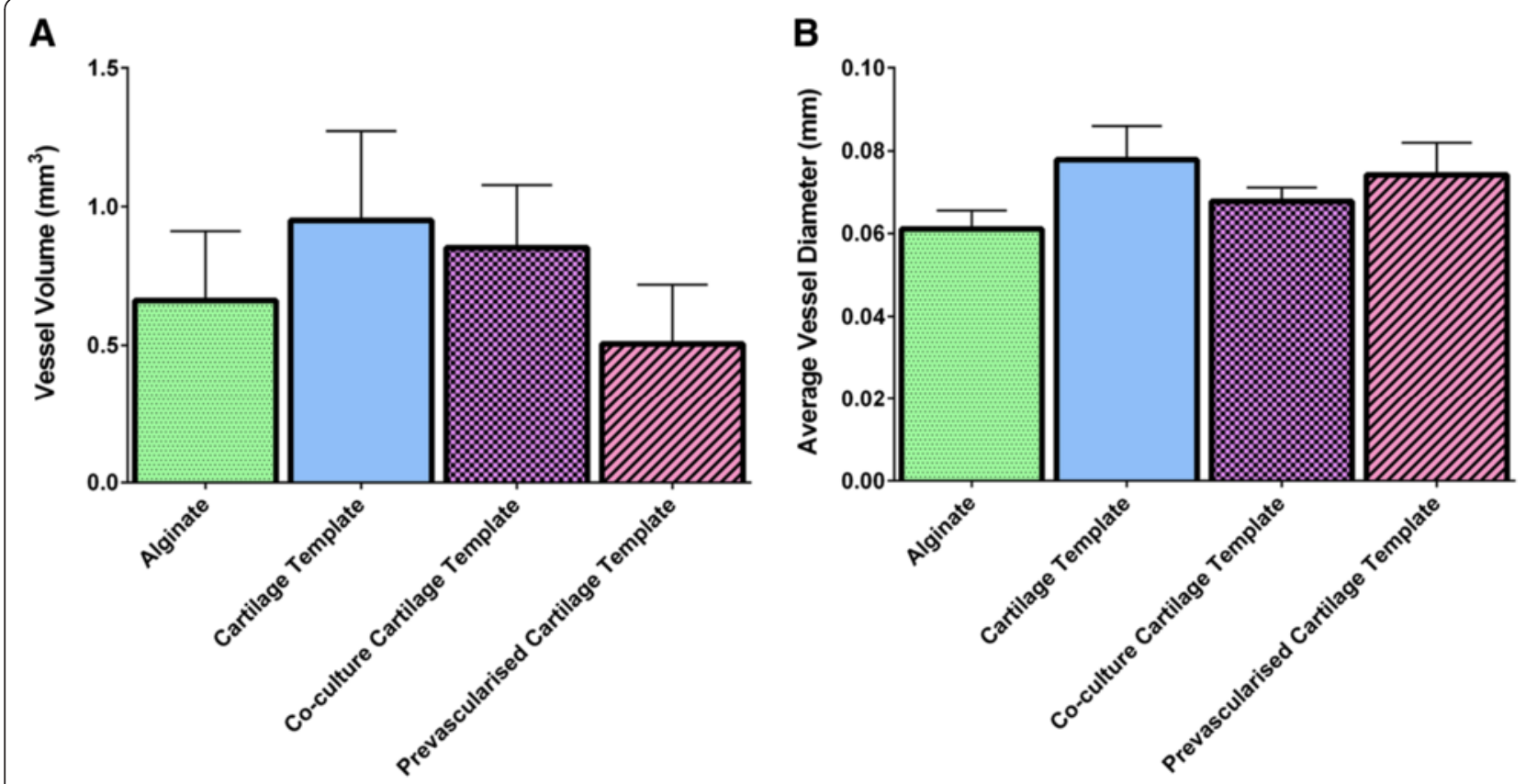

Fig. 7 a Total vessel volume and $\mathbf{b}$ average vessel diameter demonstrating the level of vessel formation within the implanted constructs after 4 weeks

established in vitro can be maintained when implanted in vivo [43-48]. In this study we investigated whether prevascularisation of chondrogenically primed constructs in vitro prior to implantation could overcome limitations of vascularisation and thus degradation of the implanted constructs and uneven mineral distribution. The results from this study show that vessel formation was achieved within the constructs of all groups after 4 weeks implantation (as indicated by $\mu \mathrm{CT}$ angiography, Masson's Trichrome and $\alpha$-smooth actin staining). However, the only group to have vessel formation within the aggregates, and not just in the surrounding alginate or in the periphery of the aggregate, was the pre-vascularised cartilaginous aggregates. This may be due to the fact it was also the only group to have rudimentary vessels present prior to implantation (as indicated by CD31 staining). Moreover, it was also the only group to have mature vessels complete with a smooth muscle lining (as indicated by $\alpha$-smooth actin staining) and red blood cells (as indicated by Masson's Trichrome). The pre-vascularised cartilaginous aggregates also had the thickest vessel diameters present within the constructs as a whole (as indicated by $\mu \mathrm{CT}$ angiography), with five out of eight of the rats having vessels with diameters between 0.15 and $0.35 \mathrm{~mm}$ and these vessels accounted for up to $14 \%$ of the overall vessels present within the constructs. Moreover, the prevascularised cartilaginous aggregates were the only group to have viable cells 21 days after implantation. Previous studies have only shown maintenance of viable MSCs to 7 days [57]. Taken together, these results indicate that pre- vascularisation of the cartilaginous aggregates prior to implantation exerts a positive effect on maintenance of the viability of implanted human stem cells in aggregates implanted for 4 weeks in vivo and this is directly associated with the formation of mature vessels present within the centre of the aggregates.

MSCs are a perivascular cell type [65-67], and have been shown to have pro-angiographic effects on endothelial cells when co-cultured in vitro [54, 68]. Our results show both the perivascular role of MSCs in vivo and the pro-angiographic effects on endothelial cells, as the only group to form vessels within the cellular aggregates were the pre-vascularised cartilaginous group, which had both MSCs and HUVECs added to the cartilage template. Interestingly, immunohistochemical staining also revealed that the HUVECs that were added to the already formed cartilage template (in the Co-culture Cartilage Template group and the Pre-vascularised Cartilage Template group) were not just present around the periphery of the aggregates but were also present within the surrounding alginate. Moreover, these HUVECs were shown to play a role in the formation of the mature vessels and integrate with the host cells to form vessels (as indicated by CD31 staining). However, whether it is the human MSCs added during the co-culture or the human MSCs used to form the cartilage template, or the host MSCs that are involved in the formation of these vessels is still unknown. The CD31 stain used was specific for human cells and the persistent staining by 4 weeks after implantation confirms that human cells 

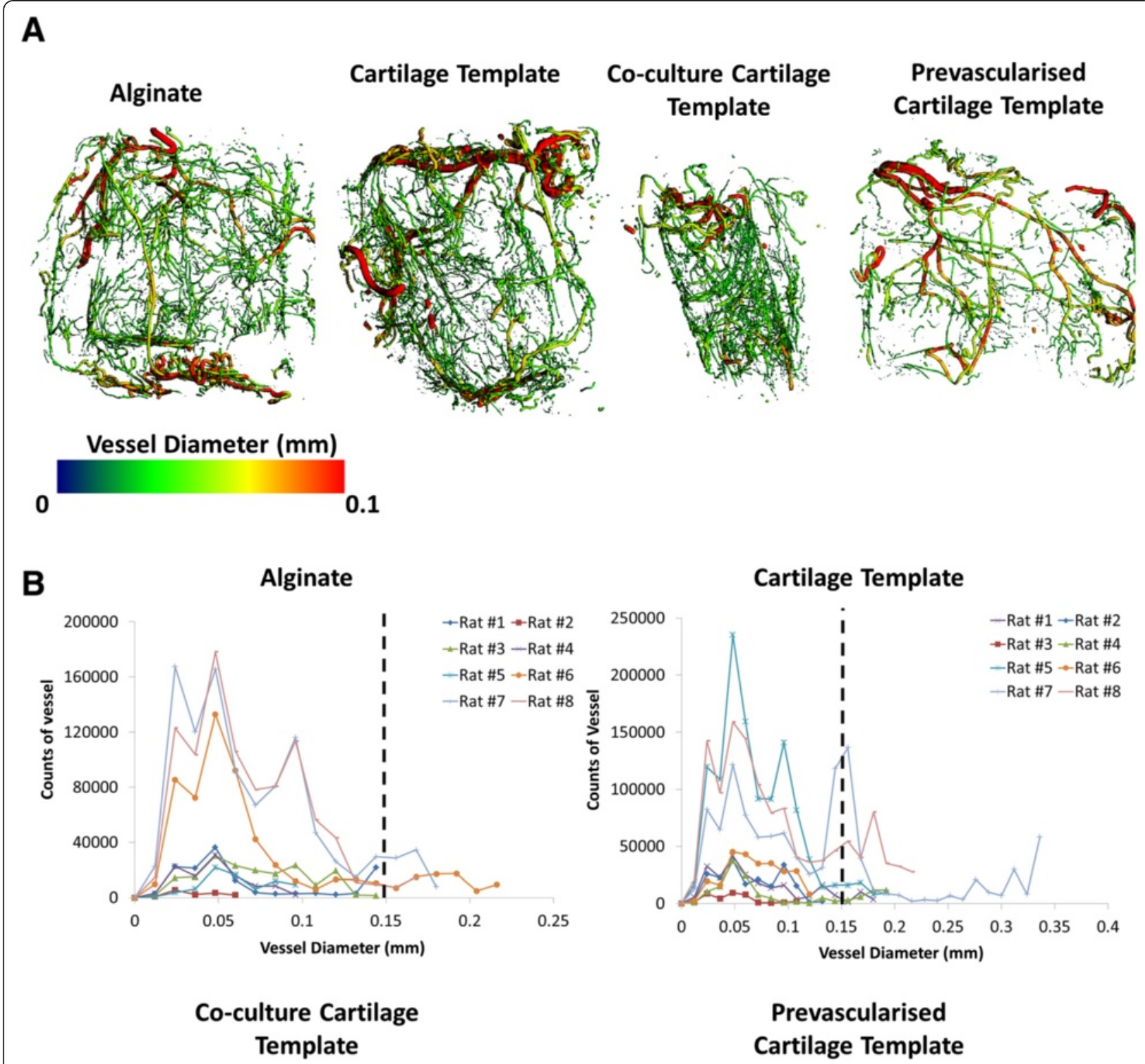

\section{Prevascularised \\ Cartilage Template}
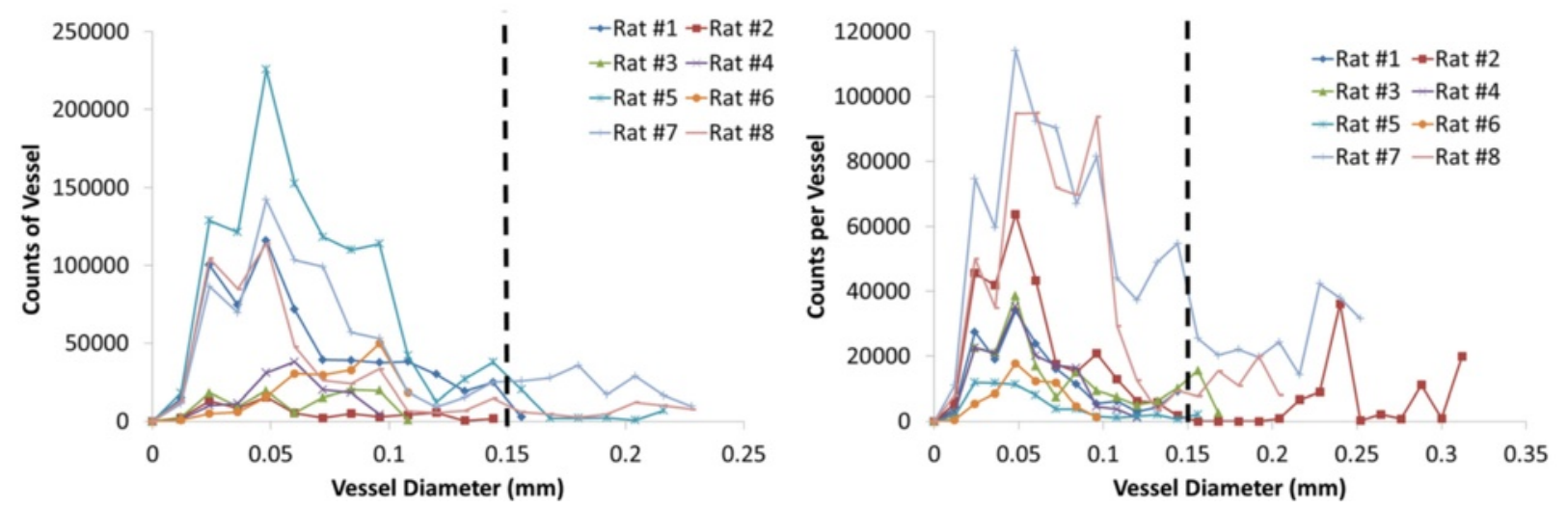

Fig. 8 a Microcomputed tomography angiography representative images of vessel diameter and $\mathbf{b}$ histograms of vessel diameters from all planes of the construct for each group, demonstrating the varying vessel thickness of the vessels present after 4 weeks 


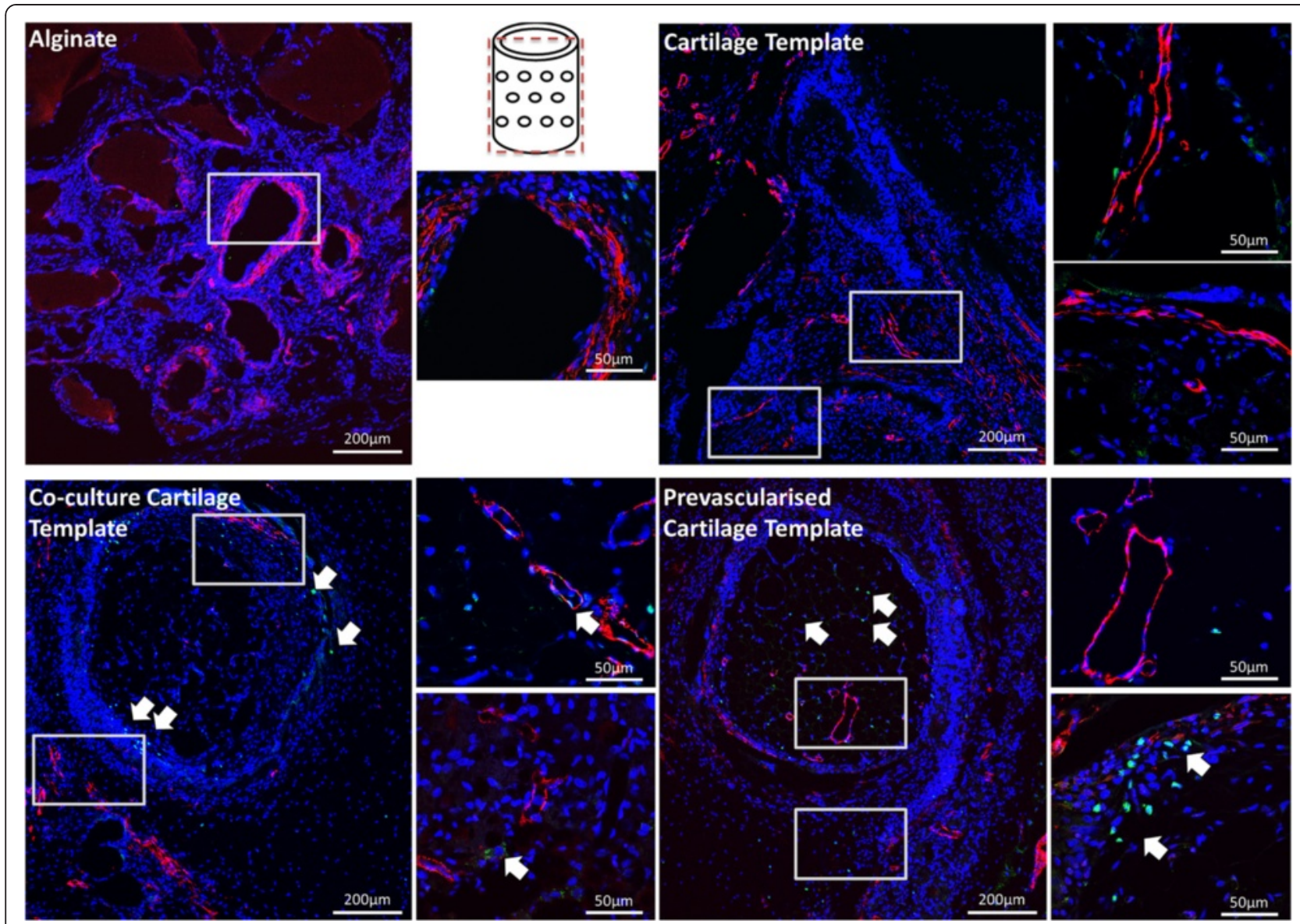

Fig. 9 Immunohistochemical staining of the groups after 4 weeks implantation. Boxes denote area of magnification. Images were taken at 10x and $60 \times$. Schematic of the plane in which the section was taken is in the middle of the image. CD31 stained in green, nucleus stained in blue, smooth actin stained in red. Arrows denote presence of CD31 (green) within vessel formation

did persist and may be involved in the formation of the vascular networks. Further studies are needed to elucidate which cells types are involved in forming the vessels observed here.

Unlike other studies [43-48] this study did not use a scaffold. One of the major limitations to current scaffold tissue engineering studies is the inhomogeneous distribution of cells within the construct [69]. This uneven distribution can then lead to heterogeneous properties, fibrous tissue encapsulation [13], and degradation within the centre of the construct, which ultimately leads to the degradation of the scaffold itself [13, 20-26]. Our approach allows the cells to form their own scaffold, mimicking native endochondral ossification, therefore ameliorating the distribution of cells. Previously we have shown that chondrogenically priming MSCs in vitro, to form a cartilage template, provides a suitable scaffold for HUVECs and MSCs to attach, proliferate, infiltrate, and ultimately form rudimentary vessels [54]. This study not only verifies the benefits of this scaffold-less setup but also shows that, even after being implanted for 4 weeks, there was minimal degradation of the centre of the aggregates in the cartilage template of the prevascularised cartilaginous aggregates. In contrast, the non-pre-vascularised groups had fibrous tissue present surrounding the aggregates, which can lead to hypertrophy of the cells in the centre of the aggregate and hence the degradation of the centre of the aggregates (seen in the Masson's Trichrome).

During endochondral ossification, angiogenesis occurs once the cartilage template has formed. This process involves endothelial cells invading through the cartilage canals already present in the developing bone tissue [27-30], and typically occurs between 14 and 18 days of embryogenesis [30, 31]. Therefore in order for mineralisation to occur, the cartilage template must be formed, and vessel infiltration must then occur. Previous studies, which have looked at just the formation of the cartilage template through the subcutaneous implantation of either chondrogenically primed construct [25, 26, 36, 37] or hypertrophic constructs $[33,38]$, found little to no mineral formation before 8 weeks in vivo. This study 


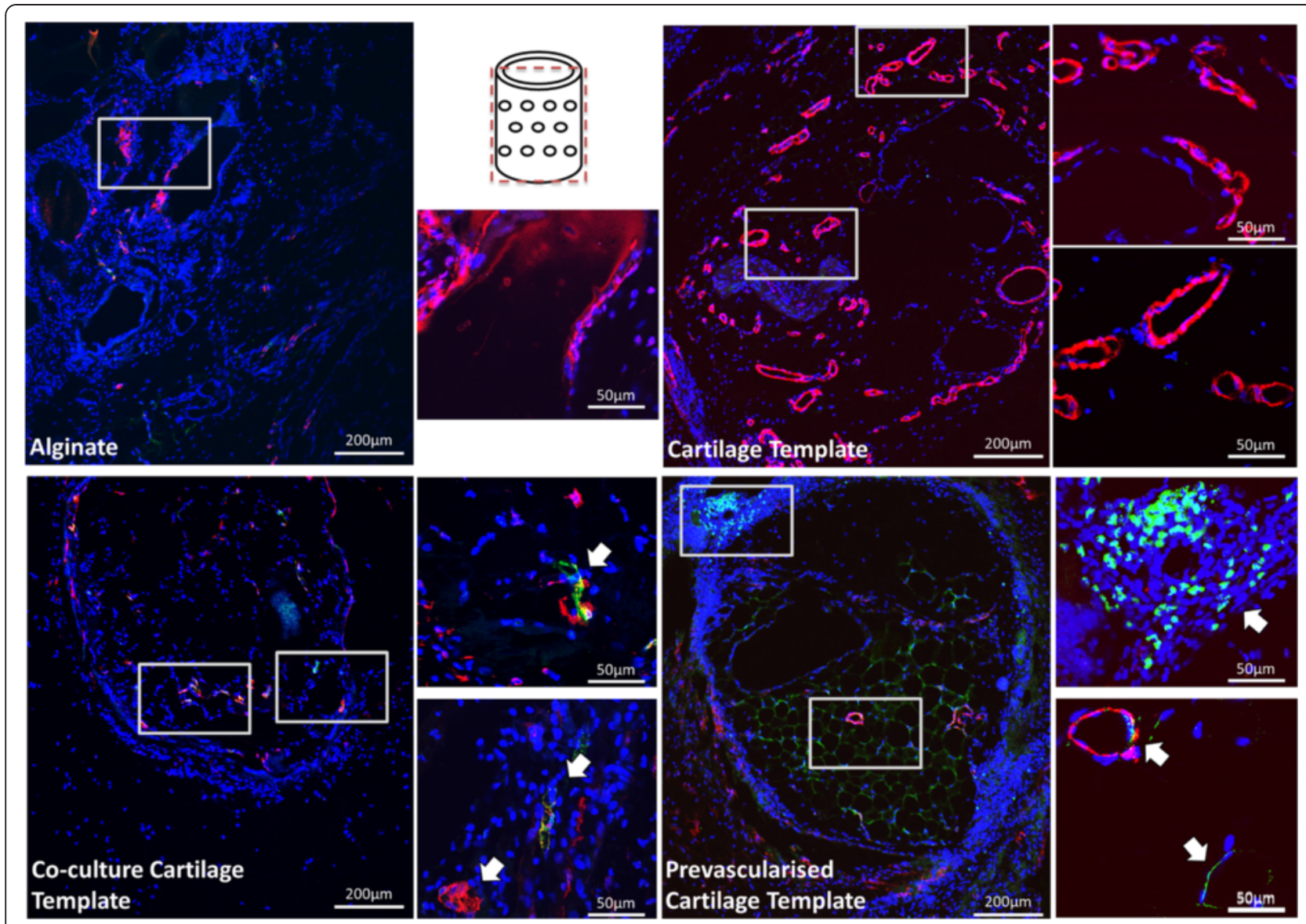

Fig. 10 Immunohistochemical staining of the groups after 4 weeks implantation. Boxes denote area of magnification. Images were taken at 10x and $60 \times$. Schematic of the plane in which the section was taken is in the middle of the image. CD146 stained in green, nucleus stained in blue, smooth actin stained in red. Arrows denote presence of CD146 within vessel formation

found that there was mineralisation present in all of the groups after 4 weeks in this ectopic bone model. Alizarin Red staining of the groups also shows that mineralisation nodules were present predominately in the surrounding Alginate. As the alginate contained BMP-2 this was to be expected. However, the only group that had mineralisation nodules present within the centre of the aggregates was the pre-vascularised cartilaginous aggregates. Our previous in vitro study found that when both MSCs and HUVECs were added to a chondrogenically primed aggregate, mineralisation was reduced, compared to the addition of HUVECs alone [54]. Furthermore, this mineral was characterised by the formation of discrete mineralised nodules rather than homogenous mineralisation throughout the construct, similar to those seen in this study. Researchers have postulated that, in order to mimic bone formation that occurs naturally during the early fetal development, vasculogenesis should be induced prior to osteogenesis in vitro in order to obtain functional bone tissue when implanted in vivo [30, 43, 54]. The results from this study are in agreement with such theories, as the only aggregates to have mineralisation nodules present within the aggregates were also the only group to have mature vessels present within the aggregate. We propose that mineralisation deposition does not occur until after vessel formation, and that this was a possible explanation for why mineralisation was not seen in the chondrogenically primed aggregates (without and with HUVECS alone) as vascularisation within the centre of the aggregate had not occurred. However, mineralisation nodules were beginning to form in the pre-vascularised group but only once mature vessels had formed within the aggregates. Moreover, mineralisation only occurred within close proximately of these vessels. Therefore, it is possible that culturing this group in vivo for longer than 4 weeks will ultimately allow for enhanced mineralisation, but this cannot be verified from the results of the current study and future in vivo investigations are required.

\section{Conclusions}

This study shows for the first time that a tissue regeneration approach that incorporates both chondrogenic 
priming of MSCs to first form a cartilage template, and subsequent pre-vascularisation of the cartilage constructs through the co-culture of HUVECs and MSCs in vitro improves implanted stem cell viability, vessel formation (as indicated by $\alpha$-smooth muscle actin walls and red blood vessels) and mineral formation once implanted in vivo. Specifically, the results from this study show that the only group to have mature vessels present within the aggregates after 4 weeks in vivo was the pre-vascularised cartilaginous aggregates. We propose that this vascularisation exerted a positive effect on the viability of implanted stem cells and mineralisation potential of the aggregate, as it was also the only group to have both viable cells 21 days after implantation and mineralisation nodules present within the aggregates. Taken together, these results indicate that endochondral priming of MSC aggregates can increase the survivability of implanted cells, which then contribute to vascularisation of the aggregate and mineral deposition of tissue engineering constructs once implanted in vivo. Future bone tissue engineering strategies could be designed with these conditions in mind such that the factors needed to mimic the endochondral ossification process are incorporated to the point where the constructs themselves can autonomously progress to engraftment, remodelling and ultimately tissue regeneration.

\section{Abbreviations \\ ALP: Alkaline phosphatase; ANOVA: Analyses of variance; BLI: Bioluminescent imaging; BMP: Bone morphogenetic protein; BSA: Bovine serum albumin; CP: Chondrogenically primed; DAPI: 4',6-Diamidino-2-phenylindole; DMEM: Dulbecco's modified Eagle's medium; EDTA: Ethylenediaminetetraacetic acid; EGM: Endothelial growth medium; FBS: Fetal bovine serum; GAG: Glycosaminoglycan; GFP: Green fluorescent protein; HUVEC: Human umbilical vein endothelial cell; ITS: Insulin-transferrin-selenium; Luc: Firefly luciferase; MOI: Multiplicity of infection; MSC: Mesenchymal stem cell; NBF: Neutral buffered formalin; NGS: Normal goat serum; PBS: Phosphate- buffered saline; PCL: Polycaprolactone; PSL: Penicillin/streptomycin/L-glutamine; ROI: Region of interest; TGF: Transforming growth factor; aMEM: Minimum essential medium alpha; $\mu \mathrm{CT}$ : Microcomputed tomography.}

\section{Competing interests}

The authors declare that they have no competing interests.

\section{Authors' contributions}

FEF, HYS, REG and LMM conceived and designed the experiments. ABA and FEF performed the operations and the vascular perfusion. FEF performed the experimental characterisation, obtained the data and performed the statistical analysis. All authors analysed the data and drafted the manuscript, and all authors read and approved the final manuscript.

\section{Acknowledgements}

The confocal imaging was performed at the Centre for Microscopy and Imaging, National University of Ireland Galway, Ireland, with special thanks to Peter Owens for allowing the use of the microscope. This study was supported by the European Research Council Grant 258992BONEMECHBIO and the NUI Travelling Scholarship 2013. This work was supported by the Army, Navy, NIH, Air Force, VA and Health Affairs to support the AFIRM II effort, under Award No. W81XWH-14-2-0003. The U.S. Army Medical Research Acquisition Activity, 820 Chandler Street, Fort Detrick MD 21702-5014 is the awarding and administering acquisition office. Opinions, interpretations, conclusions and recommendations are those of the author and are not necessarily endorsed by the Department of Defence.

\section{Author details}

Centre for Biomechanics Research (BMEC), Biomedical Engineering, College of Engineering and Informatics, National University of Ireland Galway, Galway, Ireland. 'Wallace H. Coulter Department of Biomedical Engineering, Parker H. Petit Institute for Bioengineering \& Bioscience, Georgia Institute of Technology, 315 Ferst Drive NW, Atlanta, GA 30332, USA. ${ }^{3}$ George W. Woodruff School of Mechanical Engineering, Parker H. Petit Institute for Bioengineering \& Bioscience, Georgia Institute of Technology, 315 Ferst Drive NW, Atlanta, GA 30332, USA.

Received: 12 May 2015 Revised: 2 October 2015

Accepted: 21 October 2015 Published online: 05 November 2015

\section{References}

1. Verbruggen SW, Vaughan TJ, MCNamara LM. Strain amplification in bone mechanobiology: a computational investigation of the in vivo mechanics of osteocytes. J R Soc Interface. 2012;9(75):2735-44.

2. Dawson Jl, Oreffo RO. Bridging the regeneration gap: stem cells, biomaterials and clinical translation in bone tissue engineering. Arch Biochem Biophys. 2008;473(2):124-31.

3. Cancedda R, Giannoni P, Mastrogiacomo M. A tissue engineering approach to bone repair in large animal models and in clinical practice. Biomaterials. 2007;28(29):4240-50.

4. Rose FR, Oreffo RO. Bone tissue engineering: hope vs hype. Biochem Biophys Res Commun. 2002;292(1):1-7.

5. Bruder SP, Kraus KH, Goldberg VM, Kadiyala S. The effect of implants loaded with autologous mesenchymal stem cells on the healing of canine segmental bone defects. J Bone Joint Surg Am. 1998;80(7):985-96.

6. Williams JM, Adewunmi A, Schek RM, Flanagan CL, Krebsbach PH, Feinberg $\mathrm{SE}$, et al. Bone tissue engineering using polycaprolactone scaffolds fabricated via selective laser sintering. Biomaterials. 2005;26(23):4817-27.

7. Mathieu LM, Mueller TL, Bourban PE, Pioletti DP, Muller R, Manson JA. Architecture and properties of anisotropic polymer composite scaffolds for bone tissue engineering. Biomaterials. 2006;27(6):905-16.

8. Marra KG, Szem JW, Kumta PN, DiMilla PA, Weiss LE. In vitro analysis of biodegradable polymer blend/hydroxyapatite composites for bone tissue engineering. J Biomed Mater Res. 1999;47(3):324-35.

9. Uemura T, Dong J, Wang Y, Kojima H, Saito T, lejima D, et al. Transplantation of cultured bone cells using combinations of scaffolds and culture techniques. Biomaterials. 2003;24(13):2277-86.

10. Yang XB, Roach HI, Clarke NM, Howdle SM, Quirk R, Shakesheff KM, et al. Human osteoprogenitor growth and differentiation on synthetic biodegradable structures after surface modification. Bone. 2001;29(6):523-31.

11. Yang XB, Bhatnagar RS, Li S, Oreffo RO. Biomimetic collagen scaffolds for human bone cell growth and differentiation. Tissue Eng. 2004;10(7-8):1148-59.

12. MacArthur BD, Oreffo RO. Bridging the gap. Nature. 2005;433(7021):19.

13. Lyons FG, Al-Munajjed AA, Kieran SM, Toner ME, Murphy CM, Duffy GP, et al. The healing of bony defects by cell-free collagen-based scaffolds compared to stem cell-seeded tissue engineered constructs. Biomaterials. 2010;31(35):9232-43.

14. Meijer GJ, de Bruijn JD, Koole R, van Blitterswijk CA. Cell based bone tissue engineering in jaw defects. Biomaterials. 2008;29(21):3053-61.

15. Ohgushi H, Goldberg VM, Caplan Al. Repair of bone defects with marrow cells and porous ceramic. Experiments in rats. Acta Orthop Scand. 1989;60(3):334-9.

16. Nerem RM, Sambanis A. Tissue engineering: from biology to biological substitutes. Tissue Eng. 1995;1(1):3-13.

17. Schantz J-T, Hutmacher DW, Lam CXF, Brinkmann M, Wong KM, Lim TC, et al. Repair of calvarial defects with customised tissue-engineered bone grafts II. Evaluation of cellular efficiency and efficacy in vivo. Tissue Eng. 2003;9(4, Supplement 1):127-39.

18. Dupont KM, Sharma K, Stevens HY, Boerckel JD, García AJ, Guldberg RE. Human stem cell delivery for treatment of large segmental bone defects. Proc Natl Acad Sci. 2010;107(8):3305-10.

19. Rai B, Lin JL, Lim ZXH, Guldberg RE, Hutmacher DW, Cool SM. Differences between in vitro viability and differentiation and in vivo bone-forming efficacy of human mesenchymal stem cells cultured on PCL-TCP scaffolds. Biomaterials. 2010;31(31):7960-70.

20. Amini AR, Laurencin CT, Nukavarapu SP. Bone tissue engineering: recent advances and challenges. Crit Rev Biomed Eng. 2012;40(5):363-408. 
21. O'Brien FJ. Biomaterials and scaffolds for tissue engineering. Materials Today. 2011;14(3):88-95.

22. Phelps EA, Garcia AJ. Update on therapeutic vascularization strategies. Regen Med. 2009;4(1):65-80.

23. Ko HC, Milthorpe BK, McFarland CD. Engineering thick tissues-the vascularisation problem. Eur Cells Mater. 2007;14:1-18. discussion 19

24. Krishnan L, Willett N, Guldberg R. Vascularization strategies for bone regeneration. Ann Biomed Eng. 2014;42(2):432-44.

25. Farrell E, Both SK, Odorfer Kl, Koevoet W, Kops N, O'Brien FJ, et al. In-vivo generation of bone via endochondral ossification by in-vitro chondrogenic priming of adult human and rat mesenchymal stem cells. BMC Musculoskelet Disord. 2011;12:31.

26. Farrell E, van der Jagt OP, Koevoet W, Kops N, van Manen CJ, Hellingman CA, et al. Chondrogenic priming of human bone marrow stromal cells: a better route to bone repair? Tissue Eng Part C. 2009;15(2):285-95.

27. Mackie EJ, Ahmed YA, Tatarczuch L, Chen KS, Mirams M. Endochondral ossification: how cartilage is converted into bone in the developing skeleton. Int J Biochem Cell Biol. 2008;40(1):46-62.

28. McNamara L. Bone as a Material_-Intramembranous Ossification. In: Ducheyne P, Hutmacher DE, Grainger DE, James C, editors. Comprehensive Biomaterials. 6. UK: Elsevier; 2011. p. 4000.

29. Kronenberg HM. Developmental regulation of the growth plate. Nature. 2003;423(6937):332-6.

30. Gerber HP, Ferrara N. Angiogenesis and bone growth. Trends Cardiovasc Med. 2000;10(5):223-8.

31. Carlevaro MF, Cermelli S, Cancedda R, Descalzi Cancedda F. Vascular endothelial growth factor (VEGF) in cartilage neovascularization and chondrocyte differentiation: auto-paracrine role during endochondral bone formation. J Cell Sci. 2000;113(Pt 1):59-69.

32. Oliveira SM, Amaral IF, Barbosa MA, Teixeira CC. Engineering endochondral bone: in vitro studies. Tissue Eng Part A. 2009;15(3):625-34.

33. Scotti C, Tonnarelli B, Papadimitropoulos A, Scherberich A, Schaeren S, Schauerte A, et al. Recapitulation of endochondral bone formation using human adult mesenchymal stem cells as a paradigm for developmental engineering. Proc Natl Acad Sci. 2010;107(16):7251-6.

34. Freeman FE, Haugh MG, McNamara LM. Investigation of the optimal timing for chondrogenic priming of MSCs to enhance osteogenic differentiation in vitro as a bone tissue engineering strategy. J Tissue Eng Regen Med. 2013. doi:10.1002/term.1793.

35. Pfander D, Gelse K. Hypoxia and osteoarthritis: how chondrocytes survive hypoxic environments. Curr Opin Rheumatol. 2007;19(5):457-62.

36. Jukes JM, Both SK, Leusink A, Sterk LMT, van Blitterswijk CA, de Boer J. Endochondral bone tissue engineering using embryonic stem cells. Proc Natl Acad Sci. 2008;105(19):6840-5.

37. Oliveira SM, Mijares DQ, Turner G, Amaral IF, Barbosa MA, Teixeira CC. Engineering endochondral bone: in vivo studies. Tissue Eng A. 2009;15(3):635-43.

38. Scotti C, Piccinini E, Takizawa H, Todorov A, Bourgine P, Papadimitropoulos $A$, et al. Engineering of a functional bone organ through endochondral ossification. Proc Natl Acad Sci. 2013;110(10):3997-4002.

39. Harada N, Watanabe $Y$, Sato K, Abe S, Yamanaka K, Sakai Y, et al. Bone regeneration in a massive rat femur defect through endochondral ossification achieved with chondrogenically differentiated MSCs in a degradable scaffold. Biomaterials. 2014;35(27):7800-10.

40. van der Stok J, Koolen MK, Jahr H, Kops N, Waarsing JH, Weinans H, et al. Chondrogenically differentiated mesenchymal stromal cell pellets stimulate endochondral bone regeneration in critical-sized bone defects. Eur Cells Mater. 2014;27:137-48. discussion 48.

41. Rivron NC, Liu JJ, Rouwkema J, de Boer J, van Blitterswijk CA. Engineering vascularised tissues in vitro. Eur Cells Mater. 2008;15:27-40.

42. Kanczler JM, Oreffo RO. Osteogenesis and angiogenesis: the potential for engineering bone. Eur Cells Mater. 2008;15:100-14.

43. Correia C, Grayson WL, Park M, Hutton D, Zhou B, Guo XE, et al. In vitro model of vascularized bone: synergizing vascular development and osteogenesis. PLoS One. 2011;6(12):28352.

44. Ghanaati S, Fuchs S, Webber MJ, Orth C, Barbeck M, Gomes ME, et al. Rapid vascularization of starch-poly(caprolactone) in vivo by outgrowth endothelial cells in co-culture with primary osteoblasts. J Tissue Eng Regen Med. 2011;5(6):136-43.

45. Pedersen TO, Blois AL, Xing Z, Xue $Y$, Sun $Y$, Finne-Wistrand $A$, et al. Endothelial microvascular networks affect gene-expression profiles and osteogenic potential of tissue-engineered constructs. Stem Cell Res Therapy. 2013:4(3):52.

46. McFadden TM, Duffy GP, Allen AB, Stevens HY, Schwarzmaier SM, Plesnila N, et al. The delayed addition of human mesenchymal stem cells to pre-formed endothelial cell networks results in functional vascularization of a collagenglycosaminoglycan scaffold in vivo. Acta Biomater. 2013;9(12):9303-16.

47. Duffy GP, McFadden TM, Byrne EM, Gill SL, Farrell E, O'Brien FJ. Towards in vitro vascularisation of collagen-GAG scaffolds. Eur Cells Mater. 2011;21:15-30.

48. Scherberich A, Galli R, Jaquiery C, Farhadi J, Martin I. Three-dimensiona perfusion culture of human adipose tissue-derived endothelial and osteoblastic progenitors generates osteogenic constructs with intrinsic vascularization capacity. Stem Cells. 2007;25(7):1823-9.

49. Villars F, Bordenave L, Bareille R, Amedee J. Effect of human endothelial cells on human bone marrow stromal cell phenotype: role of VEGF? J Cell Biochemistry. 2000;79(4):672-85.

50. Sun H, Qu Z, Guo Y, Zang G, Yang B. In vitro and in vivo effects of rat kidney vascular endothelial cells on osteogenesis of rat bone marrow mesenchymal stem cells growing on polylactide-glycoli acid (PLGA) scaffolds. Biomed Eng Online. 2007;6:41.

51. Liao J, Hammerick KE, Challen GA, Goodell MA, Kasper FK, Mikos AG. Investigating the role of hematopoietic stem and progenitor cells in regulating the osteogenic differentiation of mesenchymal stem cells in vitro. J Orthopaed Res. 2011;29(10):1544-53.

52. Rouwkema J, de Boer J, Van Blitterswijk CA. Endothelial cells assemble into a 3-dimensional prevascular network in a bone tissue engineering construct. Tissue Eng. 2006;12(9):2685-93.

53. Saleh FA, Whyte M, Genever PG. Effects of endothelial cells on human mesenchymal stem cell activity in a three-dimensional in vitro model. Eur Cells Mater. 2011;22:242-57. discussion 57.

54. Freeman $\mathrm{FE}$, Haugh MG, McNamara L. An in vitro bone tissue regeneration strategy combining chondrogenic and vascular priming enhances the mineralisation potential of MSCs in vitro whilst also allowing for vessel formation. Tissue Eng A. 2015;21(7-8):1320-32.

55. Sheyn D, Kallai I, Tawackoli W, Cohn Yakubovich D, Oh A, Su S, et al. Genemodified adult stem cells regenerate vertebral bone defect in a rat model. Mol Pharm. 2011;8(5):1592-601.

56. Sun $\mathrm{N}$, Lee $\mathrm{A}, \mathrm{Wu} \mathrm{JC}$. Long term non-invasive imaging of embryonic stem cells using reporter genes. Nat Protoc. 2009;4(8):1192-201.

57. Allen AB, Gazit Z, Su S, Stevens HY, Guldberg RE. In Vivo Bioluminescent Tracking of Mesenchymal Stem Cells Within Large Hydrogel Constructs. Tissue Engineering Part C: Methods. 2014;20(10):806-16. doi:10.1089/ ten.TEC.2013.0587.

58. Korff T, Augustin HG. Integration of endothelial cells in multicellular spheroids prevents apoptosis and induces differentiation. J Cell Biol. 1998;143(5):1341-52.

59. Kolambkar YM, Dupont KM, Boerckel JD, Huebsch N, Mooney DJ, Hutmacher DW, et al. An alginate-based hybrid system for growth factor delivery in the functional repair of large bone defects. Biomaterials. 2011;32(1):65-74.

60. Duvall CL, Taylor WR, Weiss D, Guldberg RE. Quantitative microcomputed tomography analysis of collateral vessel development after ischemic injury. Am J Physiol Heart Circ Physiol. 2004;287(1):H302-10.

61. Nyangoga H, Mercier P, Libouban H, Basle MF, Chappard D. Threedimensional characterization of the vascular bed in bone metastasis of the rat by microcomputed tomography (MicroCT). PLoS One. 2011;6(3), e17336.

62. Young S, Kretlow JD, Nguyen C, Bashoura AG, Baggett LS, Jansen JA, et al. Microcomputed tomography characterization of neovascularization in bone tissue engineering applications. Tissue Eng Part B Rev. 2008;14(3):295-306.

63. Mendes SC, Tibbe JM, Veenhof M, Both S, Oner FC, van Blitterswijk CA, et al. Relation between in vitro and in vivo osteogenic potential of cultured human bone marrow stromal cells. J Mater Sci Mater Med. 2004;15(10):1123-8.

64. Kuznetsov SA, Krebsbach PH, Satomura K, Kerr J, Riminucci M, Benayahu D, et al. Single-colony derived strains of human marrow stromal fibroblasts form bone after transplantation in vivo. J Bone Miner Res. 1997;12(9):1335-47.

65. Caplan Al. All MSCs are pericytes? Cell Stem Cell. 2008;3(3):229-30

66. Crisan M, Yap S, Casteilla L, Chen CW, Corselli M, Park TS, et al. A perivascular origin for mesenchymal stem cells in multiple human organs. Cell Stem Cell. 2008;3(3):301-13

67. Melero-Martin JM, De Obaldia ME, Kang SY, Khan ZA, Yuan L, Oettgen P, et al. Engineering robust and functional vascular networks in vivo with 
human adult and cord blood-derived progenitor cells. Circ Res. 2008;103(2):194-202.

68. Hung SC, Pochampally RR, Chen SC, Hsu SC, Prockop DJ. Angiogenic effects of human multipotent stromal cell conditioned medium activate the PI3KAkt pathway in hypoxic endothelial cells to inhibit apoptosis, increase survival, and stimulate angiogenesis. Stem Cells. 2007;25(9):2363-70.

69. Chan BP, Leong KW. Scaffolding in tissue engineering: general approaches and tissue-specific considerations. Eur Spine J. 2008;17 Suppl 4:467-79.

Submit your next manuscript to BioMed Central and take full advantage of:

- Convenient online submission

- Thorough peer review

- No space constraints or color figure charges

- Immediate publication on acceptance

- Inclusion in PubMed, CAS, Scopus and Google Scholar

- Research which is freely available for redistribution 